\title{
Molecular Basis of Primary Hyperparathyroidism
}

\author{
${ }^{1,2,4}$ Peyman Björklund, ${ }^{1,2}$ Lee F Starker, ${ }^{1,2}$ Annabelle L Fonseca, ${ }^{1,2,3}$ Tobias Carling \\ ${ }^{1}$ Department of Surgery, Yale University School of Medicine, New Haven, CT, USA \\ ${ }^{2}$ Yale Endocrine Neoplasia Laboratory, Yale University School of Medicine, New Haven, CT, USA \\ ${ }^{3}$ Cancer Genetics Program, Yale Cancer Center, Yale University School of Medicine, New Haven, CT, USA \\ ${ }^{4}$ Department of Surgical Sciences, Uppsala University, Uppsala, Sweden
}

Correspondence: Tobias Carling, Department of Surgery, Yale Endocrine Neoplasia Laboratory, Yale University School of Medicine, 333 Cedar Street, TMP202, Box 208062, New Haven, CT 06520, Phone: +1-203-737-2036, Fax: +1-203 737-4067 e-mail: tobias.carling@yale.edu

\begin{abstract}
During the past decade and a half, studies of genetic predisposition, parathyroid tumorigenesis, and molecular genetics of familial hyperparathyroid disorders have started to unveil the molecular basis of pHPT. Primary HPT is found in several distinct disorders with autosomal dominant inheritance such as in multiple endocrine neoplasia type 1 (MEN1), MEN2A, the HPT-jaw tumor syndrome (HPT-JT), familial isolated hyperparathyroidism (FIHPT), autosomal dominant mild hyperparathyroidism (ADMH), and neonatal severe HPT (NSHPT).

Keywords: Primary hyperparathyroidism, familial, multiglandular.
\end{abstract}

\section{INTRODUCTION}

Primary hyperparathyroidism (pHPT) is common and with population-based screening suggest a prevalence of up to $2.3 \%$ in postmenopausal women. ${ }^{1}$ pHPT of nonfamilial ("sporadic") origin may be attributed to a benign, single adenoma in approximately $85 \%$ of patients, to multiglandular parathyroid hyperplasia in about $15 \%$, and, rarely to parathyroid carcinoma in less than $1 \%$ of cases. Although, predominantly a sporadic disorder, pHPT may also be part of various inherited tumor-susceptibility syndromes such as in multiple endocrine neoplasia type 1 (MEN1), MEN2A, the HPT-jaw tumor syndrome (HPTJT), familial isolated hyperparathyroidism (FIHPT), autosomal dominant mild hyperparathyroidism (ADMH), and neonatal severe HPT (NSHPT; Table 1). ${ }^{2,3}$

During the past decade and a half, studies of genetic predisposition, parathyroid tumorigenesis, and molecular genetics of familial hyperparathyroid disorders have started to unveil the molecular basis of pHPT.

\section{Genetic Predisposition to Primary Hyperparathyroidism}

There are reasons to believe that the etiology of clinically apparently nonfamilial cases of pHPT is dependent upon inherited genetic predisposition. The first genetic association study in endocrine tumor disease was performed in patients with sporadic pHPT. ${ }^{4}$ It was demonstrated that certain naturally occurring genotypes of the vitamin $\mathrm{D}$ receptor (VDR) were overrepresented in pHPT, especially in postmenopausal female patients. Furthermore, these genotypes were associated with enhanced dysregulation of the calcium-controlled PTH secretion and reduced expression of VDR mRNA in parathyroid adenomas. ${ }^{5,6}$ Thus, an individual's VDR genotype may induce reduced parathyroid VDR expression causing impaired inhibitory effects by $1,25(\mathrm{OH})_{2} \mathrm{D}_{3}$ on parathyroid cell proliferation and PTH secretion, and thereby contribute to a higher life-time risk of developing pHPT. The association between VDR polymorphisms and primary HPT was corroborated in other cohorts of patients from the USA and Germany. ${ }^{7}$ The precise molecular mechanism of these associations are not known and requires further exploration. With the completion of the Human Genome Project in 2003 and the International HapMap Project in 2005, large-scale genome-wide association studies (GWAS) have proved to be a powerful tool in identifying genetic loci of importance to genetic susceptibility to a number of disease processes lacking classical Mandelian inheritance. ${ }^{8}$ To date, no GWAS has been performed to identify susceptibility loci for PHPT, but 
Table 1: Familial hyperparathyroid disorders, genetic characteristics, presentation of hyperparathyroidism and associated features

\begin{tabular}{|c|c|c|c|c|c|}
\hline Disorder & Inheritance & Responsible gene & Chromosomal location & $H P T$ & Associated tumors \\
\hline MEN1 & $\mathrm{AD}$ & MEN1 & $11 q 13$ & $\begin{array}{l}\text { High penetrance ( 90\%), } \\
\text { Multiglandular }\end{array}$ & $\begin{array}{l}\text { Pituitary, EPT } \\
\text { adrenocortical, carcinoid }\end{array}$ \\
\hline MEN1-variant & $\mathrm{AD}$ & $C D K N 1 B / p 27$ & 12p12-13 & Multiglandular & Pituitary \\
\hline MEN2A & $\mathrm{AD}$ & $R E T$ & $10 q 21$ & $\begin{array}{l}\text { Low penetrance ( 20\%), } \\
\text { Multiglandular/Adenoma }\end{array}$ & MTC, pheochromocytoma \\
\hline HPT-JT & $\mathrm{AD}$ & HRPT2 & 1q21-q32 & $\begin{array}{l}\text { Cystic parathyroid tumors, } \\
15 \% \text { risk of carcinoma }\end{array}$ & Jaw tumors, renal lesions \\
\hline \multirow[t]{3}{*}{ FIHPT $^{\mathrm{a}}$} & $\mathrm{AD}$ & HRPT2 & 1q21-q32 & Adenoma/multiglandular & - \\
\hline & $\mathrm{AD}$ & MEN1 & 11q13 & $"$ & - \\
\hline & $\mathrm{AD}$ & $?$ & 2p13.3-14 & $"$ & - \\
\hline ADMH & $\mathrm{AD}$ & CASR & 3q13-21 & Multiglandular/Adenoma & - \\
\hline FHH & $\mathrm{AD}$ & CASR & $3 q 13-21$ & Mildly hyperplastic & - \\
\hline NSHPT & $\mathrm{AR} / \mathrm{AD}$ & CASR & $3 q 13-21$ & Markedly hyperplastic & - \\
\hline
\end{tabular}

MEN_multiple endocrine neoplasia; HPT-JT_hereditary hyperparathyroidism-jaw tumor syndrome; FIHPT_Familial isolated hyperparathyroidism; ADMH—autosomal dominant mild hyperparathyroidism; FHH—familial hypocalciuric hypercalcemia; NSHPT — neonatal severe hyperparathyroidism; AD—autosomal dominant; AR — autosomal recessive; EPT_endocrine pancreatic tumors; MTC-medullary thyroid carcinoma. a Some studies indicate linkage to the HPT-JT locus at 1q21-q32, whereas some kindreds exhibit mutations in the MEN1 gene at 11q13, or linkage to a novel locus on 2p13.3-14. Most typical presentation of HPT and most common associated tumors are presented, but variations exist within and between families.

such studies are likely to bring important insights into the genetic predisposition of the disease.

\section{Clonality of Parathyroid Tumors}

DNA polymorphism-based approaches demonstrated that most, if not all, sporadic parathyroid adenomas are monoclonal lesions, arising from a single precursor cell with a selective growth advantage relative to the surrounding tissue. ${ }^{9}$ Monoclonality was also demonstrated in some lesions classified as sporadic primary parathyroid hyperplasia and most pathological parathyroid glands excised at surgery for severe secondary HPT due to renal failure. ${ }^{10}$ As such, the severe hyperparathyroidism of renal failure can now be classified as a neoplastic disorder. It is therefore conceivable that the growth of one or more monoclonal parathyroid neoplasms on the background of generalized hyperplasia is critical for the development of HPT refractory to standard medical therapy and requiring surgical treatment. Not surprisingly, parathyroid carcinoma, like other malignancies, also demonstrates monoclonality. ${ }^{11}$ These findings motivated detailed studies on somatic genetic events involved in parathyroid tumorigenesis.

\section{Parathyroid Oncogene Activation}

The cyclin D1 oncogene, now recognized to have a central role in many forms of human neoplasia, was initially identified at the breakpoint of a parathyroid adenoma DNA rearrangement. ${ }^{12,13}$ This rearrangement is a pericentromeric inversion of chromosome 11 which juxtaposes the strong tissue-specific regulatory region of the $P T H$ gene with the cyclin D1/PRAD1 gene's intact coding region, resulting in overexpression of cyclin D1. The oncogenicity of cyclin D1 overexpression has been further established in transgenic mice models. Tissue-specific enhancement of cyclin D1 expression in parathyroid glands results in development of tumors and abnormal PTH response to serum calcium. ${ }^{14,15}$ To date PTH-cyclin D1 rearrangements have been documented in only a small subset of parathyroid adenomas, while overexpression of the cyclin D1 protein has been substantiated in 18 to $40 \%$ of typical sporadic parathyroid adenomas, ${ }^{16,17}$ suggesting that $P T H$-cyclin $D 1$ gene rearrangement appear to be but one of several mechanisms causing cyclin D1 overexpression.

Cyclin D1 is a target of the wnt $/ \beta$-catenin signaling pathway. ${ }^{18}$ Aberrations within the wnt/ $\beta$-catenin signaling pathway have been identified in a variety of parathyroid tumors. ${ }^{19-21}$ In a Swedish cohort, 7\% of examined tumors displayed activating mutations in exon 3 of $\beta$-catenin. However, other studies have failed to show any such mutations. ${ }^{22,23}$ An aberrantly spliced, internally truncated variant of LRP5, a co-receptor for wnt ligands, resulting in stabilization and accumulation of $\beta$-catenin seem to be present in a majority of parathyroid tumors of $\mathrm{pHPT}^{24}$ 
Additional parathyroid oncogenes are likely to be identified. The whole genome of 53 parathyroid adenomas was searched for DNA amplifications by the comparative genomic hybridization technique. DNA amplifications were detected at chromosomes 16p and 19p in approximately $10 \%$ of the parathyroid adenomas, suggesting the presence of putative oncogenes at these loci. ${ }^{25}$

\section{Parathyroid Tumor Suppressor Gene Inactivation}

Allelic loss (loss of heterozygosity; LOH) of chromosomal loci may identify tumor suppressor genes in neoplasia. $\mathrm{LOH}$ at the MEN type 1 locus on chromosome band 11q13 has been demonstrated in approximately 25 to $40 \%$ of sporadic parathyroid adenomas, and somatic homozygous mutations of the recently identified MEN1 gene are found in 12 to $17 \%$ of adenomas, or about $50 \%$ of those tumors with $\mathrm{LOH}$ at $11 \mathrm{q} 13 .{ }^{26-28}$ These findings clearly indicate that mutational aberrations in the MEN1 gene contribute to parathyroid tumorigenesis, but also raise the possibility that 11q13 may harbor an additional parathyroid tumor suppressor gene. Functional aspects of the MEN1 gene product are addressed in the discussion of familial hyperparathyroidism below. Comprehensive $\mathrm{LOH}$ and comparative genomic hybridization studies of parathyroid adenomas have identified locations for several other candidate tumor suppressor gene loci such as $1 \mathrm{p}, 1 \mathrm{q}, 6 \mathrm{q}, 9 \mathrm{p}, 11 \mathrm{p}, 15 \mathrm{q} \cdot{ }^{25}$ To date no gene other than MEN1 and HRPT2 have been proven by somatic mutation to be a tumor suppressor in parathyroid adenomas. Mutations in the well-characterized tumor suppressor genes $p 53$ and $R B$ do not appear to contribute to the development of parathyroid adenomas. ${ }^{11,29}$ However, hypermethylation of the retinoblastoma interacting zinc finger gene (RIZ1) is common in parathyroid tumors. ${ }^{30}$ $p 15^{I N K 4 d}, p 16^{I N K 4 a}$, and $p 18^{I N K 4 c}$, members of the INK-4 family of cyclin dependent kinase inhibitors which antagonize the actions of cyclin D1, have also been analyzed in parathyroid adenomas but no mutational aberrations were detected. ${ }^{31,32}$ Immunohistochemical studies of the p27, a member of CIP/KIP family of cyclin-dependent kinase inhibitors, showed a decreasing level of protein expression in normal, hyperplastic, adenomatous, and malignant parathyroid glands, respectively. ${ }^{33}$ While it has been speculated that p27 possesses tumor suppressor activity and diminished protein expression could be involved in the progression of parathyroid tumors, pathogenetic mutations in the $\mathrm{p} 27^{\mathrm{KIP} 1}$ gene are rare in human tumors and have been only reported in very few human parathyroid tumors. ${ }^{34,35}$
The theoretically appealing possibility that somatic inactivating mutations in the calcium sensing receptor (CASR) and VDR genes are involved in parathyroid tumor formation has been investigated, but no such mutations were detected. ${ }^{36}$ Genes involved in basic cellular processes such as repair of damaged DNA and replication are of interest, given the association of parathyroid neoplasia with radiation exposure. Two such genes investigated to date, $R A D 51$ and $R A D 54$, are not somatically mutated in parathyroid adenomas and are unlikely to contribute to parathyroid tumorigenesis. ${ }^{37,38}$

Recent studies showed involvement of Klotho in regulation of apoptosis, ${ }^{39}$ and calcium homeostasis. ${ }^{40}$ Klotho inhibits canonical Wnt signaling by binding to Wnt3. ${ }^{41}$ Klotho functions as a coreceptor for FGFR1 (IIIc) for FGF23, and modulates FGF23 signaling. ${ }^{42}$ In parathyroid glands, Klotho seems to have a dual function. It stimulates secretion of PTH directly by recruitment of $\mathrm{Na}^{+} / \mathrm{K}^{+}$ATPases, ${ }^{40}$ and suppress PTH secretion indirectly through FGF23. ${ }^{43}$ Klotho expression is down regulated in parathyroid tumors of pHPT and its expression correlates with serum calcium and tumor size. ${ }^{44}$ While Klotho has been suggested to be a tumor suppressor gene involved in regulation of insulin-like growth factor (IGF) signaling in breast, ovarian and cervical cancer, its role in parathyroid tumorigenesis remain unclear.

\section{Sporadic Primary Parathyroid Hyperplasia and Parathyroid Carcinoma}

Although, the term "hyperplasia” intuitively denotes a generalized polyclonal growth process, a substantial minority of parathyroid lesions defined as sporadic primary parathyroid hyperplasia were in fact found to be of monoclonal origin. ${ }^{10}$ This finding adds biological weight to the point that histopathological examination of a single hypercellular parathyroid gland cannot definitively distinguish adenoma from hyperplasia. Hyperplasia is only able to be diagnosed clinically with the knowledge that multiple glands are enlarged, and it is now clear that a subset of such glands have undergone clonal neoplastic outgrowth. Some sporadic primary hyperplasias seem to harbor somatic mutations in the MEN1 gene. ${ }^{26,28}$ Generally, however, it appears that a different pattern of acquired genetic alteration may be present in sporadic hyperplasias in comparison to parathyroid adenomas. ${ }^{45}$

Parathyroid carcinoma is rare and despite some recent efforts, ${ }^{46}$ is virtually impossible to definitively distinguish from an "atypical” adenoma unless extensive locoregional 
invasion or distant metastases are present. Investigation of the $R B$ tumor suppressor gene at chromosome $13 q$ identified $\mathrm{LOH}$ in all parathyroid carcinomas of the 5 investigated patients, and was associated with an absence of immunostaining for the $\mathrm{Rb}$ protein. ${ }^{11}$ Subsequent studies confirmed that allelic loss on chromosome 13q, appears to be frequent in clinically and histopathologically aggressive parathyroid tumors, including parathyroid carcinoma. ${ }^{47-48}$ Somatic mutations of the HRPT2 gene (encoding parafibromin) seem common in parathyroid carcinomas. ${ }^{49}$ Studies surveying the genomes of parathyroid cancers have identified a very different pattern of somatic DNA gains and losses than are characteristic of benign adenomas. These differences, including evidence that MEN1/11q13 defects are rare in carcinomas, suggest that carcinomas generally arise de novo rather than from preexisting adenomas, and that genetic analysis may assist in the often difficult distinction between malignant and benign parathyroid neoplasia. ${ }^{50}$

\section{FAMILIAL PARATHYROID DISORDERS}

Many insights into tumorigenesis have been gathered from studies on inherited tumor-susceptibility disorders, and parathyroid tumors are no exception in this respect. Primary HPT is found in several distinct disorders with autosomal dominant inheritance such as such as in multiple endocrine neoplasia type 1 (MEN1), MEN2A, the HPT-jaw tumor syndrome (HPT-JT), familial isolated hyperparathyroidism (FIHPT), autosomal dominant mild hyperparathyroidism $(\mathrm{ADMH})$, and neonatal severe HPT (NSHPT). ${ }^{3,30}$

\section{Multiple Endocrine Neoplasia Syndromes}

MEN 1 is an inherited predisposition to neoplasia at several sites including parathyroid, endocrine pancreas and anterior pituitary glands. HPT is the most penetrant component of the syndrome, affecting approximately $90 \%$ of the patients, and consists almost invariably of multiple parathyroid tumors. ${ }^{51}$ The MEN 1 genetic locus was mapped to chromosome band 11q13 in the late 1980's and the MEN1 gene, encoding a 610-amino acid protein (menin), was subsequently identified by positional cloning. ${ }^{52}$ Mutational aberrations including deletions, insertions, missense-, frameshift- and nonsense mutations of the MEN1 gene have been detected in 75 to $90 \%$ of the MEN 1 families and in several sporadic endocrine tumors. Many of the mutations are predicted to cause a nonfunctioning, inactive protein, which is in agreement with the proposed role for MEN1 as a tumor suppressor gene. The mutations are scattered throughout the 10 exons of the MEN1 gene and there are no apparent genotype-phenotype correlations in terms of specific mutations and the clinical presentation of the disorder. Tumors associated with MEN 1 typically demonstrate $\mathrm{LOH}$ at chromosome 11q13, which is consistent with the 2-hit Knudson hypothesis, suggesting that inactivation of the normal allele inherited from the unaffected parent is necessary for tumor formation, similar to the genetics of familial retinoblastoma. The DNA sequence of the MEN1 gene initially gave no clue to the possible function of the menin protein, however, it has been demonstrated that the protein is located primarily in the cell nucleus, ${ }^{53}$ and that menin binds to the transcription factor JunD. ${ }^{54}$ Naturally occurring mutations in families with MEN type 1 cause a protein unable to interact with JunD, suggesting that the tumor suppressor activity of menin is linked to the inhibition of JunD-activated transcription. This is further strengthened by the demonstration that menin similar to JunD is expressed in the highest levels during the S-phase of the cell cycle. ${ }^{55}$

Several other interacting partners have been identified, NF-KappaB proteins (transactivation inhibition), ${ }^{56}$ Smad3 (blocking transforming growth factor type beta signaling), ${ }^{57}$ MLL1 and MLL2 (histone methyltransferase activity to epigenetically regulate gene expression), ${ }^{58,59}$ activator of S-phase kinase, DNA damage repair protein FANCD2, glial fibrillary acidic protein, metastasis suppressor nm23, myosin heavy chain and vimentin. ${ }^{60}$

The MEN 2A syndrome is diagnosed by the presence of familial medullary thyroid carcinoma (MTC) together with either HPT, pheochromocytoma or both. HPT is present in about 10 to $20 \%$ of genetically affected individuals and is generally due to multigland parathyroid enlargements. ${ }^{61}$ Heterozygous mutations in the RET protooncogene at chromosome 10q11 cause MEN 2A, as well as MEN type 2B and familial (isolated) MTC syndromes. In contrast to the huge diversity in specific MEN1 mutations, RET mutations associated with MEN 2A are in about 95\% of the cases and are localized in exons 10 and 11 of the gene. Thus, analysis of codons 609, 611, 618, 620 and 634 is usually sufficient to identify an individual MEN 2A-family's RET mutation. The RET protein belongs to the tyrosine kinase growth factor receptor family. Normally, interaction with a ligand complex comprised of the glial cell line-derived neurotrophic factor (GDNF) and GDNF family receptor alpha-1 (GFR alpha-1) is required to activate RET. ${ }^{62}$ However, RET mutations causing MEN 2A enable RET to 
be constitutively active in the absence of ligand. The low penetrance of hyperparathyroidism in MEN 2A, the low rate of recurrent HPT after subtotal parathyroidectomy, and the absence of somatic RET mutations in sporadic HPT suggest that RET mutations do not confer a particularly strong proliferative stimulus in the context of parathyroid tissue.

\section{Hyperparathyroidism-jaw Tumor Syndrome/ Familial Isolated Hyperparathyroidism}

The hereditary HPT-jaw tumor (HPT-JT) syndrome is characterized by an aggressive type of parathyroid adenoma or carcinoma in conjunction with fibro-osseous tumors of the mandibula/maxilla. The genetic locus responsible for this autosomal dominant tumor predisposition was mapped to chromosome 1q21-31, ${ }^{47,63}$ and identified as the HRPT2 tumor suppressor gene in HPT-JT, ${ }^{64}$ and parathyroid carcinomas, ${ }^{49}$ as well as a subset of FIHPT. HRPT2 encodes parafibromin, a member of the PAF complex, ${ }^{65}$ which seems to act as a suppressor of the c-myc oncogene. ${ }^{66}$

More than 100 familial HPT kindreds have been identified without any biochemical or radiological signs of the MEN syndromes or lesions associated with the HPT-JT syndrome. ${ }^{67}$ This entity is generally described as familial isolated HPT (FIHPT). Some FIHPT families are MEN1variants, with none of the extra-parathyroid manifestations of MEN1 but with documented mutations in the MEN1 gene. ${ }^{68,69}$ The reason why these patients fail to develop other endocrine tumors is not understood.

\section{Familial Hypocalciuric Hypercalcemia and Neonatal Severe Hyperparathyroidism}

Familial hypocalciuric hypercalcemia (FHH) is inherited as an autosomal dominant trait with moderate hypercalcemia, inappropriately normal or slightly elevated serum PTH levels, low urinary calcium excretion, apparently normal parathyroid histology, and tendencies towards hypermagnesemia. ${ }^{70}$ The disorder should be distinguished from $\mathrm{pHPT}$, since it is generally asymptomatic and requires no treatment. A major genetic locus for FHH was mapped to chromosome 3q21-24, and shortly thereafter it was shown that the disorder can be caused by heterozygous inactivating mutations in the CASR gene. ${ }^{71}$ Genetic heterogeneity exists; in some FHH families the disorder is linked to chromosome 19q and in some linkage to both chromosomes $3 q$ and $19 q$ has been excluded. More than 25 such mutations have been identified in FHH, and these point mutations have been confined to exons 2 to 4 and 7, which encode the extracellular and transmembrane domains of the protein. ${ }^{72}$ Expression of the CASR mutants, mainly in human embryonic kidney cells (HEK293), demonstrated that the mutated CASRs exhibit varying degrees of inactivation ranging from only modest right-shifts in the $\mathrm{EC}_{50}$ for extracellular calcium effects on intracellular calcium concentrations $\left[\left(\mathrm{Ca}^{2+}\right)_{\mathrm{i}}\right]$ to complete functional inactivation. ${ }^{72}$ The functional basis for receptor inactivation can vary: some CASR mutants may not reach the cell surface, others seem to have reduced affinity for calcium, mutations in the transmembrane region have been speculated to affect the signal transduction of CASR, and some, when expressed on the cell surface, seem to compete with the normal receptor in the interaction with other proteins. ${ }^{72}$ Because the CASR is expressed in multiple tissues in addition to parathyroid and kidney, these CASR mutations confer a generalized insensitivity to calcium that explains the absence of end-organ damage or symptoms of hypercalcemia typical of FHH.

Interestingly, in one FHH family a repetitive DNA sequence was inserted in the intracellular domain-encoding region of $C A S R$, with a predicted truncation of the protein. ${ }^{73}$ Three of the heterozygous family members developed HPT, which indicates not only that some FHH families may be associated with a less benign phenotype than previously anticipated but also that certain alterations in the intracellular domain of the CASR can promote parathyroid cell proliferation. Moreover, one large family has been described with a germline CASR mutation and a autosomal dominant phenotype different from FHH and FIHPT. ${ }^{74}$ Affected patients had hypercalcemia, hypercalciuria, serum PTH levels within the upper part of the normal range, and a history of renal stones. Genetic studies identified a novel atypical inactivating mutation in the intracellular part of the CASR. Thus, some families with inactivating germline mutations in the CASR may develop parathyroid tumors and clinical characteristics more similar to that seen in primary HPT than in typical FHH. ${ }^{74}$ This has been corroborated in a recent study employing DNA sequencing of a large series of patients with various forms of hypercalcemia. ${ }^{75}$

In contrast to FHH, NSHPT is a severe disorder characterized by marked hypercalcemia, dramatically elevated serum PTH levels, marked parathyroid hyperplasia and hyperparathyroid bone disease. ${ }^{70}$ Affected individuals typically present symptoms at birth, with failure to thrive, skeletal deformity and respiratory complications, and the disease is accompanied by substantial mortality unless parathyroid surgery or intensive medical intervention is 
performed immediately. ${ }^{70}$ Since NSHPT may be found in FHH families, it was natural to search for CASR mutations in these subjects. It was shown that most often NSHPT is associated with homozygous inactivating mutations of the CASR gene, but some subjects exhibit heterozygous mutations as well. NSHPT exhibits the same variability in CASR mutations as does FHH, and transfection of mutant CASRs into HEK293 cells generally demonstrates a marked right-shift in the $\mathrm{EC}_{50}$ for calcium controlled $\left[\mathrm{Ca}^{2+}\right]_{\mathrm{i}}{ }^{72}$ The relationship between FHH and NSHPT was well-illustrated by heterozygous and homozygous inactivation of the CASR in mice, which developed phenotypes very similar to FHH and NSHPT, respectively. ${ }^{76}$

\section{FUTURE STUDIES}

With the technological explosion in molecular genetics and cancer genetics, it is likely that the next decade will continue to bring important insights into the molecular pathology of primary hyperparathyroidism. The ability to perform whole genome genotyping, copy number variation analysis, whole exome capture and massively parallel DNA sequencing of matched parathyroid tumor and germline DNA as well as quantitative whole genome DNA methylation analysis represents just a few recent genomic techniques to further characterize the molecular basis of primary HPT.

\section{ACKNOWLEDGMENTS}

Dr. Björklund is supported by the Astrid Karlsson Foundation and a Postdoctoral Fellowship Award from the Swedish Society for Medical Research. Dr. Carling is supported in part by a Damon Runyon Clinical Investigator Award from the Damon Runyon Cancer Research Foundation and a Doris Duke Clinical Scientist Development Award from the Doris Duke Charitable Foundation.

\section{REFERENCES}

1. Lundgren E, Rastad J, Åkerström G, Ljunghall S. Populationbased health screening for primary hyperparathyroidism with serum calcium and parathyroid hormone values in menopausal women. Surgery 1997;121:287-94.

2. Stalberg P, Carling T. Familial Parathyroid Tumors: Diagnosis and Management. World J Surg 2009.

3. Marx SJ SW, Agarwal SK, Burns AL, Weinstein LS, Cochran C, Skarulis MC, Spiegel AM, Libutti SK, Alexander HR Jr, Chen CC, Chang R, Chandrasekharappa SC, Collins FS. Hyperparathyroidism in hereditary syndromes: Special expressions and special managements. J Bone Miner Res 2002;Suppl 2:N37-43.
4. Carling T, Kindmark A, Hellman P, et al. Vitamin D receptor genotypes in primary hyperparathyroidism. Nat Med 1995;1:1309-11.

5. Carling T, Kindmark A, Hellman P, Holmberg L, Akerstrom G, Rastad J. Vitamin D receptor alleles b, a, and T: Risk factors for sporadic primary hyperparathyroidism (HPT) but not HPT of uremia or MEN 1. Biochem Biophys Res Commun 1997;231:329-32.

6. Carling T, Åkerström G, Rastad J, Westin G. Vitamin D receptor (VDR) and parathyroid hormone mRNA levels correspond to polymorphic VDR alleles in human parathyroid tumors. J Clin Endocrinol Metab 1998;83:2255-59.

7. Carling T. Molecular pathology of parathyroid tumors. Trends Endocrinol Metab 2001;12:53-58.

8. Feero WG, Guttmacher AE, Collins FS. Genomic medicinean updated primer. N Engl J Med 2010;362:2001-11.

9. Arnold A, Staunton CE, Kim HG, Gaz RD, Kronenberg HM. Monoclonality and abnormal parathyroid hormone genes in parathyroid adenomas. N Engl J Med 1988;318:658-62.

10. Arnold A, Brown MF, Urena P, Gaz RD, Sarfati E, Drueke TB. Monoclonality of parathyroid tumors in chronic renal failure and in primary parathyroid hyperplasia. J Clin Invest 1995;95:2047-53.

11. Cryns VL, Rubio MP, Thor AD, Louis DN, Arnold A. p53 abnormalities in human parathyroid carcinoma. J Clin Endocrinol Metab 1994;78:1320-24.

12. Arnold A, Kim HG, Gaz RD, et al. Molecular cloning and chromosomal mapping of DNA rearranged with the parathyroid hormone gene in parathyroid adenoma. J Clin Invest 1989;83:2034-40.

13. Motokura T, Bloom T, Kim HG, et al. A novel cyclin encoded by a bcl1-linked candidate oncogene. Nature 1991;350:512-15.

14. Mallya SM, Gallagher JJ, Wild YK, et al. Abnormal parathyroid cell proliferation precedes biochemical abnormalities in a mouse model of primary hyperparathyroidism. Mol Endocrinol 2005;19:2603-09.

15. Imanishi Y, Hosokawa Y, Yoshimoto K, et al. Primary hyperparathyroidism caused by parathyroid-targeted overexpression of cyclin D1 in transgenic mice. J Clin Invest 2001;107:1093-102.

16. Yi Y, Nowak NJ, Pacchia AL, Morrison C. Chromosome 11 genomic changes in parathyroid adenoma and hyperplasia: Array CGH, FISH, and tissue microarrays. Genes Chromosomes Cancer 2008;47:639-48.

17. Hsi E, Zukerberg L, Yang W-I, Arnold A. Cyclin D1/PRAD1 expression in parathyroid adenomas: An immunohistochemical study. J Clin Endocrinol Metab 1996;81:1736-39.

18. Shtutman M, Zhurinsky J, Simcha I, et al. The cyclin D1 gene is a target of the beta-catenin/LEF-1 pathway. Proc Natl Acad Sci USA 1999;96:5522-27.

19. Bjorklund P, Lindberg D, Akerstrom G, Westin G. Stabilizing mutation of CTNNB1/beta-catenin and protein accumulation analyzed in a large series of parathyroid tumors of Swedish patients. Mol Cancer 2008;7:53.

20. Bjorklund P, Akerstrom G, Westin G. Activated beta-catenin in the novel human parathyroid tumor cell line sHPT-1. Biochem Biophys Res Commun 2007;352:532-36. 
21. Bjorklund P, Akerstrom G, Westin G. Accumulation of nonphosphorylated beta-catenin and c-myc in primary and uremic secondary hyperparathyroid tumors. J Clin Endocrinol Metab 2007;92:338-44.

22. Cetani F, Pardi E, Banti C, et al. Beta-catenin activation is not involved in sporadic parathyroid carcinomas and adenomas. Endocr Relat Cancer 2010;17:1-6.

23. Costa-Guda J, Arnold A. Absence of stabilizing mutations of beta-catenin encoded by CTNNB1 exon 3 in a large series of sporadic parathyroid adenomas. J Clin Endocrinol Metab 2007;92:1564-66.

24. Bjorklund P, Akerstrom G, Westin G. An LRP5 receptor with internal deletion in hyperparathyroid tumors with implications for deregulated WNT/beta-catenin signaling. PLoS Med 2007;4:e328.

25. Palanisamy N, Imanishi Y, Rao P, Tahara H, Chaganti R, Arnold A. Novel chromosomal abnormalities identified by comparative genomic hybridization in parathyroid adenomas. J Clin Endocrinol Metab 1998;83:1766-70.

26. Carling T, Correa P, Hessman O, et al. Parathyroid MEN1 gene mutations in relation to clinical characteristics of nonfamilial primary hyperparathyroidism. J Clin Endocrinol Metab 1998;83:2960-63.

27. Farnebo F, Teh B-T, Kytölä S, et al. Alterations of the MEN1 gene in sporadic parathyroid tumors. J Clin Endocrinol Metab 1998;83:2627-30.

28. Heppner C, Kester MB, Agarwal SK, et al. Somatic mutations of the MEN1 gene in parathyroid tumours. Nature Genet 1997;16:375-78.

29. Cryns VL, Thor A, Xu HJ, et al. Loss of the retinoblastoma tumor-suppressor gene in parathyroid carcinoma. N Engl J Med 1994;330:757-61.

30. Carling T, Du Y, Fang W, Correa P, Huang S. Intragenic allelic loss and promoter hypermethylation of the RIZ1 tumor suppressor gene in parathyroid tumors and pheochromocytomas. Surgery 2003;134:932-39; discussion 9-40.

31. Tahara H, Smith A, Gaz R, Arnold A. Loss of chromosome arm 9p DNA and analysis of the p16 and p15 cyclin-dependent kinase inhibitor genes in human parathyroid adenomas. J Clin Endocr Metab 1996;81:3663-67.

32. Tahara H, Smith A, Gaz R, Zariwala M, Xiong Y, Arnold A. Parathyroid tumor suppressor on 1p: Analysis of the p18 cyclindependent kinase inhibitor gene as a candidate. J Bone Miner Res 1997;12:1330-34.

33. Erickson L, Jin L, Wollan P, Thompson G, van Heerden J, Lloyd R. Parathyroid hyperplasia, adenomas, and carcinomas: Differential expression of p27Kip1 protein. Am J Surg Pathol 1999;23:288-95.

34. Pellegata NS, Quintanilla-Martinez L, Siggelkow H, et al. Germline mutations in p27Kip1 cause a multiple endocrine neoplasia syndrome in rats and humans. Proc Natl Acad Sci USA 2006;103:15558-63.

35. Georgitsi M, Raitila A, Karhu A, et al. Germline CDKN1B/ p27Kip1 mutation in multiple endocrine neoplasia. J Clin Endocrinol Metab 2007;92:3321-25.

36. Hosokawa Y, Pollak MR, Brown EM, Arnold A. Mutational analysis of the extracellular $\mathrm{Ca}\left(2^{+}\right)$-sensing receptor gene in human parathyroid tumors. J Clin Endocrinol Metab 1995;80:3107-10.

37. Carling T, Imanishi Y, Gaz R, Arnold A. Expression and sequence analysis of rad51: A candidate tumor suppressor gene on chromosome $15 q$ in a region frequently deleted in parathyroid tumors. Clin Endo 1999;51:403-08.

38. Carling T, Imanishi Y, Gaz R, Arnold A. Analysis of the RAD54 gene on chromosome 1p as a potential tumor-suppressor gene in parathyroid adenomas. Int J Cancer 1999;83:80-82.

39. Medici D, Razzaque MS, Deluca S, et al. FGF-23-Klotho signaling stimulates proliferation and prevents vitamin Dinduced apoptosis. J Cell Biol 2008;182:459-65.

40. Imura A, Tsuji Y, Murata M, et al. Alpha-Klotho as a regulator of calcium homeostasis. Science 2007;316:1615-18.

41. Liu H, Fergusson MM, Castilho RM, et al. Augmented Wnt signaling in a mammalian model of accelerated aging. Science 2007;317:803-06.

42. Urakawa I, Yamazaki Y, Shimada T, et al. Klotho converts canonical FGF receptor into a specific receptor for FGF23. Nature 2006;444:770-74.

43. Krajisnik T, Bjorklund P, Marsell R, et al. Fibroblast growth factor-23 regulates parathyroid hormone and 1alpha-hydroxylase expression in cultured bovine parathyroid cells. J Endocrinol 2007;195:125-31.

44. Bjorklund P, Krajisnik T, Akerstrom G, Westin G, Larsson TE. Type I membrane klotho expression is decreased and inversely correlated to serum calcium in primary hyperparathyroidism. J Clin Endocrinol Metab 2008;93:4152-57.

45. Dwight T, Nelson AE, Theodosopoulos G, et al. Independent genetic events associated with the development of multiple parathyroid tumors in patients with primary hyperparathyroidism. Am J Pathol 2002;161:1299-306.

46. Juhlin CC, Nilsson IL, Johansson K, et al. Parafibromin and APC as screening markers for malignant potential in atypical parathyroid adenomas. Endocr Pathol 2010.

47. Dotzenrath C, Teh B, Farnebo F, et al. Allelic loss of the retinoblastoma tumor suppressor gene: A marker for aggressive parathyroid tumors? J Clin Endocr Metab 1996;81:3194-96.

48. Pearce S, Trump D, Wooding C, Sheepard M, Clayton R, Thakker R. Loss of heterozygosity studies at the retinoblastoma and breast cancer susceptibility (BRCA2) loci in pituitary, parathyroid, pancreatic and carcinoid tumors. Clin Endo 1996;45:195-200.

49. Shattuck TM, Valimaki S, Obara T, et al. Somatic and germline mutations of the HRPT2 gene in sporadic parathyroid carcinoma. N Engl J Med 2003;349:1722-29.

50. Haven CJ, Howell VM, Eilers PH, et al. Gene expression of parathyroid tumors: Molecular subclassification and identification of the potential malignant phenotype. Cancer Res 2004;64:7405-11.

51. Skogseid B, Rastad J, Öberg K. Multiple endocrine neoplasia type 1: Clinical features and screening. Endocrinol Metab Clin N Am 1994;23:1-18.

52. Chandrasekharappa SC, Guru SC, Manickam P, et al. Positional cloning of the gene for multiple endocrine neoplasia-type 1. Science 1997;276:404-07.

53. Guru S, Goldsmith P, Burns A, et al. Menin, the product of the MEN1 gene, is a nuclear protein. Proc Natl Acad Sci USA 1998;95:1630-34. 
54. Agarwal S, Guru S, Heppner C, et al. Menin interacts with the AP1 transcription factor JunD and represses JunD-activated transcription. Cell 1999;96:143-52.

55. Kaji H, Canaff L, Goltzman D, Hendy G. Cell cycle regulation of menin expression. Cancer Res 1999;59:5097-101.

56. Heppner C, Bilimoria KY, Agarwal SK, et al. The tumor suppressor protein menin interacts with NF-kappaB proteins and inhibits NF-kappaB-mediated transactivation. Oncogene 2001;20:4917-25.

57. Kaji H, Canaff L, Lebrun JJ, Goltzman D, Hendy GN. Inactivation of menin, a Smad3-interacting protein, blocks transforming growth factor type beta signaling. Proc Natl Acad Sci USA 2001;98:3837-42.

58. Caslini C, Yang Z, El-Osta M, Milne TA, Slany RK, Hess JL. Interaction of MLL amino terminal sequences with menin is required for transformation. Cancer Res 2007;67:7275-83.

59. Yokoyama A, Somervaille TC, Smith KS, Rozenblatt-Rosen O, Meyerson M, Cleary ML. The menin tumor suppressor protein is an essential oncogenic cofactor for MLL-associated leukemogenesis. Cell 2005;123:207-18.

60. Dreijerink KM, Hoppener JW, Timmers HM, Lips CJ. Mechanisms of disease: Multiple endocrine neoplasia type 1-relation to chromatin modifications and transcription regulation. Nat Clin Pract Endocrinol Metab 2006;2:562-70.

61. Mulligan L, Ponder B. Genetic basis of endocrine disease: Multiple endocrine neoplasia type 2. J Clin Endocrinol Metab 1995;80:1989-95.

62. Durbec P, Marcos-Gutierrez C, Kilkenny C, et al. GDNF signalling through the Ret receptor tyrosine kinase. Nature 1996;27:789-93.

63. Szabo J, Heath B, Hill VM, et al. Hereditary hyperparathyroidism-jaw tumor syndrome: The endocrine tumor gene HRPT2 maps to chromosome 1q21-q31. Am J Hum Genet 1995;56:944-50.

64. Carpten JD RC, Villablanca A, Forsberg L, Presciuttini S, et al. HRPT2, encoding parafibromin, is mutated in hyperparathyroidism-jaw tumor syndrome. Nat Genet 2002;32:676-80.

65. Wang P, Bowl MR, Bender S, et al. Parafibromin, a component of the human PAF complex, regulates growth factors and is required for embryonic development and survival in adult mice. Mol Cell Biol 2008;28:2930-40.
66. Lin L, Zhang JH, Panicker LM, Simonds WF. The parafibromin tumor suppressor protein inhibits cell proliferation by repression of the c-myc proto-oncogene. Proc Natl Acad Sci USA 2008;105:17420-25.

67. Huang S, Duh Q, Shaver J, Siperstein A, Kraimps J, Clark O. Familial hyperparathyroidism without multiple endocrine neoplasia. World J Surg 1997;1:22-28.

68. Teh B, Esapa C, Houlston R, et al. A family with isolated hyperparathyroidism segregating a missense MEN1 mutation and showing loss of the wild-type alleles in the parathyroid tumors. Am J Hum Genet 1998;63:1544-49.

69. Kassem M, Kruse T, Wong F, Larsson C, Teh B. Familial isolated hyperparathyroidism as a variant of multiple endocrine neoplasia type 1 in a large Danish pedigree. J Clin Endocrinol Metab 2000;85:165-67.

70. Chattopadhyay N, Mithal A, Brown EM. The calcium-sensing receptor: A window into the physiology and pathophysiology of mineral ion metabolism. Endocrine Rev 1996;17:289-307.

71. Pollak MR, Brown EM, Chou YH, et al. Mutations in the human $\mathrm{Ca}(2+)$-sensing receptor gene cause familial hypocalciuric hypercalcemia and neonatal severe hyperparathyroidism. Cell 1993;75:1297-303.

72. Brown E. Mutations in the calcium-sensing receptor and their clinical implications. Horm Res 1997;48:199-208.

73. Cole D, Janicic N, Salisbury S, Hendy G. Neonatal severe hyperparathyroidism, secondary hyperparathyroidism, and familial hypocalciuric hypercalcemia: Multiple different phenotypes associated with an inactivating Alu insertion mutation of the calcium-sensing receptor gene. Am J Med Genet 1997;71:202-10.

74. Carling T, Szabo E, Bai M, et al. Familial hypercalcemia and hypercalciuria caused by a novel mutation in the cytoplasmic tail of the calcium receptor. J Clin Endocrinol Metab 2000;85:2042-47.

75. Guarnieri V, Canaff L, Yun FH, et al. Calcium-sensing receptor (CASR) mutations in hypercalcemic states: Studies from a single endocrine clinic over three years. J Clin Endocrinol Metab 2010;95:1819-29.

76. Ho C, Conner DA, Pollak MR, et al. A mouse model of human familial hypocalciuric hypercalcemia and neonatal severe hyperparathyroidism. Nat Genet 1995;11:389-94. 